\title{
Technospherization and Digitalization of the Urban Habitat as the Most Urgent Factor in the Relevancy of Social Pedagogy Modernization
}

\author{
Taisiya Kolesnik*, and Elena Dergacheva \\ Bryansk State Technical University, 241035 Bryansk, Russia
}

\begin{abstract}
The processes of socialization of the individual in the conditions of substitution of the biosphere by the technosphere are analyzed. It is concluded that the rapid rate of change is aligned with the evolutionarily developed mechanisms of adaptation. This causes deterioration of human health and results in the inability of people to protect themselves from the negative effects of the anthropogenic world. At this conjuncture, the correction of the processes of socialization and adaptation, as well as the development of a system of values that provides for preserving of the biosphere world and life, become the fundamental tasks of education. The results of the analysis show that modern education is losing traction in the process of mindset formation, delegating these functions to other information spheres, virtual reality, and spontaneous areas of Masscult. As a result, the traditional socialization process is broken. Humane correction of the current trends requires a change in the philosophical strategy of education development. As a basis for such a strategy, we propose social pedagogy that directly studies the processes of socialization of individuals. The concept of this discipline allows using the socio-natural approach as the basis for analyzing the processes, taking place in the world and in life.
\end{abstract}

\section{Introduction}

In the modern period of socio-technological development, urban communities are becoming the main socio-spatial form of society's life activity. It is city that causes the maximum substitution of the natural biospheric human environment for an artificially created technogenic one, including mushrooming of digital virtual information and communication environment. The global information space of the technosphere, formed with the help of digitalization, creates new conditions for human existence and affects all aspects of his life: life, family relations, work, production. First of all, it is the urban population, being drawn into the digitalization processes, that increases steadily. If in the 19 -th century the urban population increased by only 75 million people, within 150 years (1800-1950) - by 0.7 billion, over the next 60 years (1950-2010) of the ascent of the scientific and technological revolution-by another 2.8 billion, making up in 2015 more than half of the citizens of 7.3 billion earthlings [1]. On the one hand, the transfer of active

*Corresponding author:077767475@mail.ru 
social processes to an extremely urbanized artificial (technosphere-digital) environment gives person a chance to make better use of his / her creative and professional potential, to find a way of access to a wide range of educational services and high-quality medical care, and provides new opportunities for communication, obtaining and mastering advanced knowledge and information. On the other hand, evolutionarily developed adaptation mechanisms do not provide means for rapid adaptation within a limited time to flourishing changes and the unnatural pace of life. This causes a violation of social interaction in society, deforming the behavior of its members. For example, a person's immersion in the virtual digital world leads to an explosion of mental deceases and the development of an addiction comparable in its effect on the body to alcoholic or drug one [2]. Negative factors of the urban habitat can also include: constant physiological, psychological and intellectual stress, hypodynamia, unfavorable environmental background, increased information pressure on psyche, worldview and value system of a person. As a result, we can observe the growth of so-called diseases of civilization: cardiovascular, oncologic, allergic, etc. According to WHO data, about 1.9 million people die every year in the world from diseases related to physical inactivity [3]. This is a direct consequence of the development of technologies and untimely adaptation to their consequences. So, if in an agricultural society in the production process, human physical labor was $30 \%$, and domesticated animals- $68 \%$, then at the present time only $2 \%$ of human physical energy is involved in the production process [4]. These consequences become highest-profile in the mid-twentieth century, when the hi-tech post-industrial stage of the evolution of the man-made society began in the most developed countries of the world. It is characterized by fundamental changes not only in the production sphere and lifestyle of modern people, but also by a deep transformation of natural and biological processes, as well as a widespread prevalence of biotechnological genetically modified forms of life and the loss of natural biological diversity. Since the industrial revolution $75 \%$ of the ice-free 1 Aand area has been affected by anthropogenic impact, and $85 \%$ of the wetlands have disappeared. According to data for 2020, the "living planet index" continues to decline steadily. Thus, since 1970, the population of mammals, fish, amphibians, and birds has decreased in the range from $73 \%$ to $62 \%$ (by an average of $68 \%$ ). At the same time losses of freshwater species amounted to $84 \%$ (an average of $4 \%$ per year) [5]. The agility of changes caused by spontaneous not always deliberate expansion of the boundaries of the technosphere does not stymie the ability to adapt quickly and safely to their adverse effects. Current trends require humanizing of the goals and objectives of education. The mainstream here should be a widespread fixation on the introduction of social pedagogy into the educational process, that holistically studies the processes of socialization and adaptation of a person throughout his or her life.

\section{Methods and Materials}

The systematical socio-natural approach, which was founded By V.I. Vernadsky, allows deep analyzing of the essence of all changes that take place in the society and the biosphere. Modern trends confirm the conclusions of the scientist concerning the evolution of the biosphere, which is determined not by the totality of its constituent living organisms, but by the collective human mind, that is, by the science and labor of people, relying on largescale machinery and artificial technologies [6]. If V.I. Vernadsky generally appreciated the evolutionary turn, so we can say that technogenically developing modern liberal-economic society, by improving science and technology, changes its nature fundamentally, transforms and deforms the life domain on our planet abysmally. However, changes in the biosphere, caused by society, do not improve living conditions for all life forms, inhabitting it, and the anthroposphere reaches a higher and better level of the biosphere, as V.I. Vernadsky optimistically predicted. Practically, the foremost scientists and thinkers speak of the 
biosphere's demise and the evolutionary change of life in the direction of replacing the natural world with an artificial one, about the establishment of integrated sociotechnonatural processes and genetically modified organisms on the planet $[7,8]$. Based on V. I. Vernadsky, scientists of the Bryansk scientific and philosophical school of social and technological development of the world: E.S. Demidenko, E.A. Dergacheva, N.V. Popkova, N.N. Lapchenko, A.F. Shustova and others study the processes of interrelated development of the society, the biosphere and the technosphere.

\section{Results and Discussion}

Relying on education makes purposeful regulation and review of values, behaviors, ways of self-identification, and the mindset of the members of society as a whole, possible. However, modern education is mainly aimed at training narrow specialists or professionals, serving the objects of the technosphere. His priority is training, not education. Because of this, there is a serious tendency to obsolete humanities knowledge, which is not only manysided, but carries cultural values, having responsibility for mindset development. According to the Spanish philosopher X. Ortega-y-Gasseta, such a one-sided training of functionaries, is nothing more than the training of "barbarians, knowing just one subject perfectly" [9].

People, who are made by the artificial environment, neither take into account the gathered experience of previous generations in their activities, nor they're able to realize completely the significance of the natural biosphere basis of life. The fixation of life processes within the boundaries of the technosphere and maintenance of its viability at the expense of the resources of the technosphere, erases the confines between the natural and artificial world in the human mind, creating the illusion of the omnipotence of scientific and technological progress. In our opinion, the safe expansion of the technosphere is possible only with the appropriate development of culture and education. Meanwhile, at the present stage, we observe opposite trends, when education yields its position in shaping the mindset of members of society to other information spheres and spontaneously emerged areas of mass "culture". The tendencies of purposeful reduction of the "functional capacity of the educative link" in education are evaluated By V.A. Rybin as a deformation of the traditional process of socialization of an individual, resulting in disruption of the entire modern culture functioning [10]. In our view, the current situation is a natural extension of the technical nature implanting in the development of bourgeois elites. The efforts of the "owners of the world" are aimed at fabricating human resources according to strictly defined technical characteristics (competencies) with the consciousness that can be easily manipulated for their own selfish purposes and interests. The lack of integrity of the acquired knowledge and its isolation from value system, the imposition of the so-called "clip culture", the main characteristic of which is the fragmentation and truncation of the received information, produces disadaptation of a person who cannot develop a full-fledged life strategy and does not have the skills of analyzing the processes taking place in a technogenic society. Fabricated in this way, through such education and "culture", people make up the basis of a technogenic society at its post-industrial stage of development. As E. Toffler writes "....we are ever more stuffed with short modular flashes of informationadvertising, commands, theories, some bobtailed, truncated pieces, that do not sink in our previous mental cells"[11]. If E. Toffler assesses the current state of things as a way of becoming an individual and demassifying culture, then in our opinion, the fragmentary nature of information and knowledge makes the effective manipulation of a person and his needs possible. The mosaic of knowledge does not allow a person to construct a fullfledged model of reality, to realize the laws of its development, to accept this reality and become a part of it at the same time to be separated from it, developing his own view of the 
world and life. The described process is the basis of the traditional socialization process, which is being deformed at the present stage. Modern mass culture, competing with education for the influence of shaping the mindset, offers a person just a slavish adherence, imitation and simulation, weakening the personality, blocking the ability to be straightthinking, to read the room, to appreciate the situation and the world around him and himself in this world. The virtual digital information and communication environment also offers a person a great variety of ways of socialization that differ from the traditional process. It begins to compete with the current reality for the right to mould a person, making him go through the process of socialization in a mixed reality, in which the personality changes not according to natural laws, but subordinate to unique laws of the virtual digital world [12]. The digitalization of education, which involves the transition to training with extensive use of online and digital information technologies, also contributes to the involvement of a person in the process of socialization with the predominance of virtual reality. The school is supposed to undergo a digital revolution and becomes the way of preparation for life in the digital world. According to experts, the transition to digital education will not only contribute to improving the quality of education, but also make it more accessible to all social groups $[13,14]$. However, there is a rebuttal, for example, A. Privalov believes that digitalization can only disserve education, since it is impossible to train a good specialist on the basis of a digital decoy[15]. To our opinion, it's worth agreeing, since a significant disadvantage of digitalization of education is minimizing social contacts. As a result, the skills of social interaction are not formed in real life, and it is infeasible for a person to identify himself within the society. Such an unformed person is unable to realize his professional potential in the proper way. If digital education is to socialize a person for life in the digital world, then a natural question arises: who will prepare a person for life in reality? Besides, one never knows what will happen to the population that is unable to master digital literacy due to age for example, or to adapt to the consequences of digitalization? Statistical data indicate that there is a digital divide between the older and younger generations, who adapt much faster to the introduction of digital technologies [16]. But if the younger generation suffers from excessive involvement in digital virtual reality, then older people face the difficulties of digital literacy as a factor that reduces the quality of life.

Another important problem is that the virtual digital world, and with it digitized education, eliminates the distinction between authentic and inauthentic, blunting sense of responsibility in their actions, blurring intellectual and moral values. A.G. Chernyshev warns us that the artificially created digital information space is a fundamentally different world, filled with digital decoys and exponentially growing information garbage[17]. This world is characterized by the substitution of true culture for the culture of information consumerism, and it's not a consumption of things as it was in industrial society. N.S. Rybakov notes that a new kind of dependence "individual-information-individual" is being formed [18]. Reflection and analysis become impossible due to the lack of theoretical thinking skills and inability to navigate the continuous flow of information. We can agree with A. Zinoviev's statement that the death of the intellectual factor of understanding reality leads to loosing the significance of the existence of the social life of mankind [19]. In our opinion, this is due to the gradual displacement of traditional institutions that play a significant role in the process of socialization, such as the family, church, state, and education, by the virtual digital world. Deep involving into virtual worlds constricts the horizons of human development, generates an indifferent attitude to all living things, natural and personal, distracting a person from the important problems of transforming the world of life." Despite many social contacts, people feel lonely and isolated in an artificial virtual environment. Thus, the American sociologist E. Kleinenberg, studying the problem 
of loneliness, notes continuous growth trends in the number of people living alone, especially in large cities and supercities [20].

The transfer of active social processes mainly to an artificial virtual world results in conflict situations, the inability to forge social relationships in the current reality, blurring social standings and roles of individuals. The personality formed as a result of the interaction of two realities "can be defeated by emasculated dialectic of social worlds" [12]. The result of the discrepancy between the goals and objectives of education and mass "culture", as well as disparity between the laws of socialization in current virtual reality, is the formation of a personality of a weakened, lonely doubter, who is in an eternal search for new social guidelines and behaviors. Such a person is easily controlled by manipulating the consciousness and directing the needs. The deformation of true socialized objectives and natural life needs is expressed in the preferred orientation to supersaturation and overconsumption. Deep mental dependence on these processes not only deforms the person himself, but also causes incogitant and spontaneous destruction of the biosphere world, which is the basis of life on our planet. Thus, according to the UN Program on environment and development, there is a $40 \%$ reduction in natural resources per capita compared to the 1990 s and a simultaneous increase in production and consumption by $50 \%$ [4].

\section{Conclusions}

Bowing out, education in the process of socialization and formation of the younger generation mindset and worldview doesn't give a person an opportunity to shelter himself of technogenic environment's negative factors, and least of all to fight for the preservation of the biosphere world and its life. All this indicates that there is an indispensability of changing the philosophical foundations of modern education for humane correction of transformational processes, threatening the world and life's destruction. In our opinion, it is necessary to form practice-oriented new ideology of the pedagogical and educational process. We propose social pedagogy as the basis for this new philosophy. At the same time, social pedagogy should refer not only to the laws of social life development, but also take into account the relationships built in the process of technogenic development among society, technosphere, created by it, and the transformed biosphere. Being an integrated science, social pedagogy does not have its own methodological framework. It refers to the methodologies of other sciences, interpreting them to suit its own goals and objectives. The direct influence of social philosophy on the methodological foundations of social pedagogy [21] allows us to offer a socio-natural approach as the main methodological basis of this discipline. Social pedagogy studies the processes of socialization and adaptation of a person at all stages of his life with direct reference to environmental conditions. A significant gap that does not allow producing a full-fledged strategy for human development is that it is mainly focused on the study of social patterns that affect the formation of personality. Meanwhile, as it has been proved above, a person is also formed under the influence of both material and virtual artificial man-made environment, being a part of the biosphere world as well. All these affect his ability to perceive and adapt to the accelerated growth of the artificiality of the world. This can't be ignored by social pedagogy. The introduction of social pedagogy based on a socio-natural approach will allow education, along with knowledge about the world around, to give a student the methodological basis for understanding the processes, taking place in a technogenic society and thus protect him from further rash actions in the process of technosphere expansion and to work out a fullfledged strategy for human development, which will be able to preserve the biosphereworld and life. 


\section{References}

1. E. Shcherbakova, Forecast of urban and rural population of the world (2018), http://www.demoscope.ru/

2. Internet addiction, https://ru.wikipedia.org/

3. Disease of civilization" kills almost 2 million people a year, RIA "Novosti, https://online.zakon.kz/

4. E. S. Demidenko, Interviewed by I. Nikolskaya, Bryansk teacher's newspaper, 4(907) (2020)

5. Over 50 years, the number of vertebrate populations on Earth has decreased by $68 \%$, https://forbes.kz/

6. V.I. Vernadsky, the Biosphere and noosphere, 148 (2004)

7. E.S. Demidenko, E.A. Dergacheva, From global degradation of the biosphere to changing the evolution of life: a scientific report.,12, 28 (2017), http://www.ras.ru/

8. E.S. Demidenko, E.A. Dergacheva, IOP Conference Series: Materials Science and Engineering, 753(5), 052066 (2020)

9. Ortega-and-Gasset Jose Mission of the University, 110 (2010)

10. V. A. Rybin, University of the XXI century: Anthropological perspectives of education and culture, 36 (2012)

11. E. Toffler, Thirdwave, 278 (2002)

12. N.O. Khazieva, Virtual reality as a space of socialization, Extended abstract of D.Ph. thesis: (09.00.11), 19 (2020)

13. Yu.V. Puyu, Higher education in extreme conditions or what the pandemic showed, an international interdisciplinary collective monograph, 95 (2020)

14. E.D. Platonova, Modern education: vectors of development, Digitalization of the economy and society: challenges for the education system, 299 (2018)

15. A. Privalov, About some pathetic eight trillion. - The expert, 15(1071) (2018), https://expert.ru/

16. O.A. Maksimova, Sociology and social technologies, 17(3), 103 (2018)

17. A.G. Chernyshev, Vlast, 5, 13 (2018)

18. N.S. Rybakov, Man in the modern world: crisis and globalization, International interdisciplinary collective monograph, 34 (2020)

19. A. Zinoviev, Factor of understanding, 528 (2006)

20. E. Kleinenberg, Life solo. New social reality, 9 (2014)

21. V.I. Zagvyazinsky, Social pedagogy in Russia, 15 (2019) 